\title{
Investigación \\ Territorio, patrimonio y empleo: una visión local ante el estado de la cuestión global
}

Juan Alonso Sánchez Martinez

Director de Cultura del Ayuntamiento de Loja (Granada)

\section{Resumen}

Las nuevas estrategias de desarrollo asumen como algo inevitable el reconocimiento creciente del ámbito de decisión local en materia de políticas de gestión del patrimonio. En los últimos veinte años, el patrimonio -en su nuevo estatus como activo del paisaje cultural, económico y social- ha experimentado la puesta en práctica de fórmulas de activación económica y de creación de empleo en el medio rural que deben ser evaluadas, a pesar de las dificultades que entraña profundizar en el erial informativo y estadístico que nos brinda el binomio patrimonio-empleo. Aquí nos interesa una aproximación al impacto ocupacional de estas iniciativas, que tímidamente, comienzan a aportar sus primeras noticias.

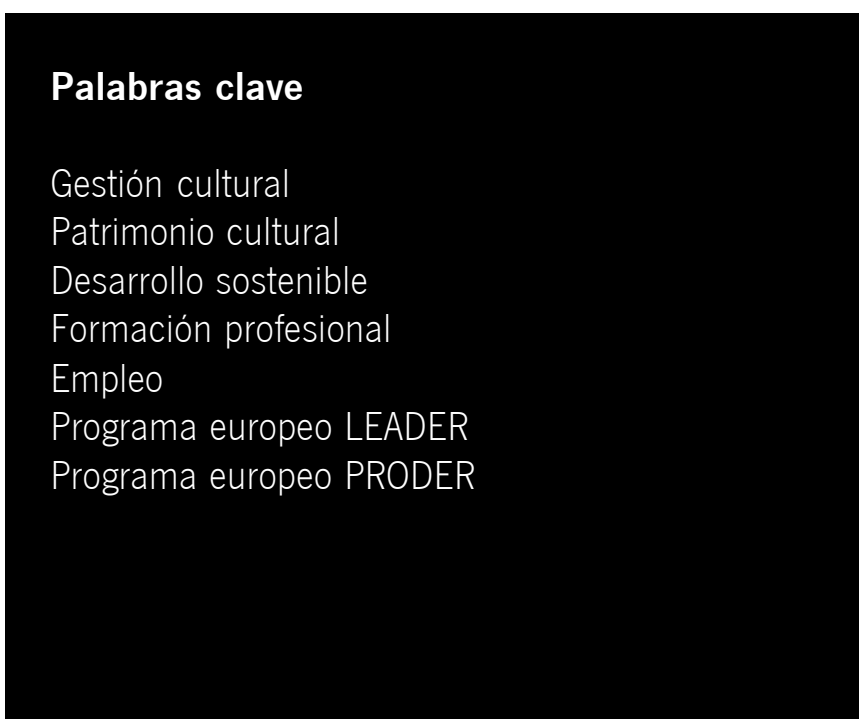

\section{Introducción}

Al amparo de las declaraciones internacionales, de sus conferencias y de sus cumbres (Río de Janeiro 1992, Aalborg 1994 y Johannesburgo 2002), el cambio de milenio ha renovado la percepción mundial sobre determinadas cuestiones de primer orden para la sostenibilidad del planeta. Las grandes contradicciones de un modelo económico que conduce a la extenuación de los recursos globales son puestas en evidencia por un nuevo concepto del ecologismo, que proclama ideas de contención y de racionalidad en el uso y el consumo de los bienes más consustanciales al territorio. Pocos nos atrevemos a cuestionar, a estas alturas del descalabro ambiental de buena parte del globo y sus regiones, la necesidad de reconducir un modelo de explotación económica demostradamente perverso, marcado por el instinto depredador de sus variopintos agentes (productores y consumidores), que hacemos tradición del hábito del avestruz, ocultando la cabeza devotos de la ceguera, gesto que como sabemos suele ser fundamento de una conciencia depurada.

Al cabo del tiempo, cada día más difusa la línea frontera entre el patrimonio natural y cultural, hacemos extensivas aquellas observaciones naturalistas al conjunto de los recursos del territorio, declinando la problemática global del planeta en sus respectivas expresiones regionales, concretando nuestras preocupaciones hasta lo local, y dotándonos de una sensibilidad con querencia al conservacionismo respecto al manejo del paisaje. Estos razonables discursos de contención, que también desarrollarán su variante más inmovilista y conservadora, coinciden en el tiempo con el ideario que propugna el desenvolvimiento de dinámicas de desarrollo territorial horizontales, en las que los propios agentes locales asumen el protagonismo de la puesta en valor de los recursos endógenos de su entorno como factores de crecimiento económico, laboral y social; como medio de generación de nuevas estrategias de porvenir.

Paralelamente, la progresiva descentralización de las estructuras politicas, en las que la colectividad asume más y más protagonismo decisorio, permite una aproximación entre el territorio y los ámbitos de dirección política y ejecutiva. La abstracción pierde vigencia en la forma de abordar el territorio y su problemática. Dicho de otro modo, un porcentaje cada día más amplio de decisiones relacionadas con los recursos patrimoniales de nuestro medio son tomadas por individuos que viven en él, que lo disfrutan y lo padecen, que lo reconocen como parte de su identidad local e inmediata, que experimentan el bochorno de la fechoría ante el rostro implacable de sus paisanos.

La "patria chica" -que la dimensión local viene a ser lo mismo- se reivindica globalmente, y anuncia una madurez creciente en medio de este marasmo, poniendo sobre la mesa casuísticas más que solventes de puesta en valor de sus recursos, generando economía 
y demanda de empleo, consolidando demografías, procurando satisfacciones, en algunos casos, incluso dando ejemplo; y superando los enfoques de la "materialidad pura" como perspectiva única para comprender el patrimonio. El contexto local actúa irremediablemente, y lo hace no sin errores, que ponen en evidencia la necesidad de superar carencias relevantes -y casi ya históricasen materia de capacitación política y profesional, de transferencia de información y de experiencias, de solvencia financiera, de agilidad y confianza entre los distintos niveles de la administración cultural para gestionar el patrimonio más allá de la simple conservación, más allá de la materialidad, más allá de la tutela en su concepto más desconfiado... pongamos que hablo del patrimonio como activo laboral y para el trabajo.

El caso es que esta nueva forma de desarrollo local, basada en el empleo razonable de los recursos, además, añade componentes de equidad territorial nada desdeñables desde la perspectiva social. Impone un modelo de usufructo extensivo del medio en el que son pocas, o ninguna, las regiones que nada tienen que decir, equilibrando el régimen de oportunidades tradicional, en el que los espacios rurales (incluso las ciudades medias) actúan como geografías claramente deficitarias, al amparo expectante de un subsidio crónico, institucionalizado, que en buena medida toma forma de planes de empleo subsistencial.

Acción y conservación, desarrollo y sostenibilidad, globalismo y localidad... definen el nuevo paradigma a resolver, en un contexto en el que los recursos patrimoniales asumen un nuevo estatus en el paisaje como activo económico, social, laboral, educativo, cultural y de ordenación del territorio; en un momento en el que los poderes locales empiezan a manejar su potencial de acción sobre los bienes patrimoniales, y en el que la financiación de sus iniciativas -tantas veces necesitadas de rumbo y capacitaciónencuentra cobertura en programas estatales y comunitarios insuficientemente tutelados por las estructuras culturales de la administración autonómica.

Se activa así una controversia ficticia y maniquea entre distintos sectores de la cultura y de la gestión territorial; en unos casos tendentes al inmovilismo y al teorema en estado puro -Dios dispone y el hombre pospone-, a la victimización de los recursos en manos de sus pobladores; en otros, acuciados por el sindrome de los balances gestores, de las tasas de desempleo, querenciados en exceso al intervencionismo de cortos plazos. Entre el nihilismo medroso y el activismo puro, la gestión de los recursos patrimoniales en el ámbito local suma y sigue, ensaya nuevos modelos de puesta en valor, tantea sus fortalezas, sus orillas y sus oportunidades; y en tanto, reivindica la legitimidad de su derecho al pequeño margen de error.

Visto lo visto -en una regresión argumental hacia las primeras líneas de este texto- posiblemente quepa también la posibilidad de atribuir al medio local un nuevo logro... ¿Causa o efecto? ¿Sujeto u objeto? Quizá estos procesos de desarrollo local, de sostenibilidad, de reivindicación territorial, no conformen necesariamente una consecuencia de las nuevas teorías científicas y económicas de los años ochenta hasta aquí. Acaso no sean el reflejo de la declaración universal de una cumbre, ni el resultado cónclave del debate experto inspirando el devenir de las sociedades. La estela de estos procesos, más bien al contrario, tal vez constituya la orientación misma de las creencias renovadas y de la especulación generada en torno a ellos, que no aspira a otra cosa que a explicar, con más o menos acierto, las cosas que pasan, las dinámicas del planeta y sus comunidades, de sus ámbitos locales, en los que el ánimo de superación de la gente abre caminos insospechados hasta en los sitios de más difícil enfoque; que ya vendrá quien los explique, negro sobre blanco, en las páginas de los impresos.

Sirvan estos apuntes para resumir una toma de posición, entiendo que pertinente, en esta sección de la revista $\mathrm{PH}$ dedicada a la reflexión y a la superposición de puntos de vista, e incluso de polémicas:

> La aparición de nuevas estrategias asociadas a la gestión de los recursos patrimoniales del territorio no debe constituir, por sí misma, una amenaza. Al contrario, supone la oportunidad de incorporar nuevas lógicas y nuevos agentes al debate de la intervención sobre los bienes culturales, que se enriquece con atributos de dinamismo, de participación y de compromiso territorial. Éste, como todo proceso que no es de coyuntura, reclama sus plazos, su espacio de ensayo y su aprendizaje.

$>$ Resulta inaplazable el reconocimiento de la mayoría de edad de los poderes locales -sensu estricto- ante la gestión del territorio y sus recursos. La asunción del principio de "co-autoría" conduce, indefectiblemente, al de "co-responsabilidad" en el diseño y aplicación de las políticas de gerencia territorial. Escatimar este estatus reciente a los diferentes agentes locales (sociales, económicos, políticos, culturales...) es un planteamiento de muy escaso recorrido histórico.

$>$ Los nuevos conceptos de uso y aprovechamiento de los recursos patrimoniales, como valores al servicio del futuro de los pueblos, significan la sustitución de los "cotos de manejo privado" tradicionales. He aquí que los recursos "patrios" aspiran a desempeñar un nuevo rol en las sociedades "glocales"; he aquí que se reivindican con ánimo protagonista y venidero, exigiendo buen trato, mesura, compromiso y profesionalidad gestora.

Los bienes patrimoniales introducen así un nuevo discurso en el desarrollo local, en la percepción de la excepcionalidad que significan, y en sus posibilidades de contribución a la idea de bienestar compartido a la que aspiramos, entre otros medios -si bien no 


\section{Investigación}

Territorio, patrimonio y empleo: una visión local ante el estado de la cuestión global

\section{J . A. Sánchez Martínez}

el único-, a través de la actividad económica y la generación de formas dignas de empleo, ya sean innovadoras o tradicionales.

El sustrato patrimonial de nuestros pueblos, durante tanto tiempo dejado "de la mano de Dios" -paradójico significado éste-, se incorpora con progresividad acelerada a la dinámica de impulso económico y ocupacional que se vislumbra en algunas de nuestras geografías locales, especialmente en aquéllas que consiguen posicionarse más y mejor como espacios singulares para un tipo determinado de producción, como enclaves estratégicos en la lógica de las comunicaciones, para la oferta de alternativas de ocio suficientemente distinguidas (cultura, turismo, deporte...), etc.

Algunos entornos locales consiguen ampliar y consolidar las estructuras económicas de su medio rural -todo sea dicho, no sin coste ambiental-, minimizando los procesos de despoblamiento y fijando a la población en sus ámbitos de origen -0 cuando no, como mal menor, en sus núcleos medios más próximos-, que ante la tozuda exigencia de su creciente ciudadanía, se ven forzados a prestar unos estándares de calidad, en todo tipo de servicios, a la altura de los televisados: en materia de abastecimientos básicos, de servicios comerciales, de transportes públicos... también en materia cultural, formativa y de promoción del empleo.

Este sencillo patrón, que desde hace años viene reestructurando el modelo demográfico de tantos territorios interiores, en los que el diseminado o la semidispersión de aldeas y pedanías tienden al agrupamiento en las cabeceras comarcales, ha amortiguado las fugas poblacionales de muchas geografías locales andaluzas hasta en los peores momentos (incluida la década de los sesenta), con unas consecuencias nada desdeñables en los procesos de desarrollo local y sus implicaciones culturales y para el empleo.

Así, no podemos dejar de considerar, entre otros efectos, la minimización del éxodo y los fenómenos de desarraigo social y productivo, de migración laboral; la atenuación en la pérdida de activos patrimoniales (intangibles, efímeros y de todo tipo) tan propios de la tradición rural; el incremento de la demanda de servicios y prestaciones sociales "in situ" (cultura, educación, educación no reglada, capacitación profesional, turismo interior...) activando yacimientos de empleo nuevos o latentes; la orientación del destino de los recursos presupuestarios locales hacia la inversión en equipamientos y programas culturales de proximidad -los propios de las cabeceras de municipios medios- ante la nueva demanda... En definitiva, la generación de estados de bienestar social en el medio local, nuevas oportunidades de empleo, conciencia de ciudadanía cualificada, de pertenencia y de identidad al territorio, que en muchas ocasiones se reivindica por medio de la valorización de sus elementos simbólicos, y entre ellos, por medio de su patrimonio histórico.
El patrimonio cultural y ambiental, fiel a su denominación de origen, aporta también elementos para la sostenibilidad laboral. En tiempos de deslocalización empresarial, de traspaso de inversiones hacia terceros paises en busca de mano de obra depreciada, el patrimonio local se reivindica como una vía de generación de empleo inamovible, ajena a las dinámicas geoestratégicas del mundo de la gran empresa. El derivado laboral de la puesta en valor del patrimonio local es de pequeña escala, propio del mundo de la microempresa o del sector público, alejado por tanto de hipotéticos extravíos geográficos.

No como algo ajeno a estos procesos -que no son unicausales-, en los últimos veinte años el medio rural se ha visto involucrado en diferentes programas públicos de desarrollo y empleo, que conscientes del papel a desempeñar por los recursos patrimoniales (culturales o naturales) en la vivificación de los contextos locales, han profundizado, más que en cualquier otro indicador de desarrollo, en la generación de empleo.

En 1988 se pusieron en marcha en nuestro país los singularísimos programas de empleo-formación conocidos como Escuelas Taller y Casas de Oficios (Instituto Nacional de Empleo), orientados a la formación y la inserción laboral de jóvenes a partir del aprendizaje práctico de oficios relacionados con la recuperación del patrimonio local. Hablamos, con toda seguridad, del programa de intervención patrimonial de más impacto social que se haya puesto en las rudas manos de los poderes locales de entonces.

El nacimiento del programa de Escuelas Taller y Casas de Oficios permitió una primera visualización de la relación existente entre el empleo y los recursos patrimoniales, no sólo recuperando arquitecturas históricas y paisajes para su puesta en valor como elementos de riqueza, sino también mediante la transmisión de destrezas artesanas hacia las nuevas generaciones académicamente menos cualificadas: durante los primeros años de aplicación del programa, años en los que la naturaleza de los proyectos mantuvieron una orientación muy preferente hacia la intervención sobre bienes culturales (1989-1996), unas cifras medias anuales de casi 16.500 jóvenes participaron del proyecto estatal, con unos índices de inserción laboral que se sostuvieron entre un $60,26 \%$ del primer ejercicio evaluado (1989) y el 58,84\% correspondiente al año 1996.

Parece evidente, a la luz de las cifras (tabla 1), que el programa de Escuelas Taller y Casas de Oficios (ET-CO) fue capaz de movilizar a un número creciente de jóvenes desempleados en un modelo de formación que tendría importantes repercusiones sobre el patrimonio local; y si bien es cierto que el programa no resultará de aplicación exclusiva en el medio rural, no menos verdad resulta el hecho de que su generalización geográfica en el conjunto del territorio español supuso una afección destacadísima en el contexto local más reducido. 


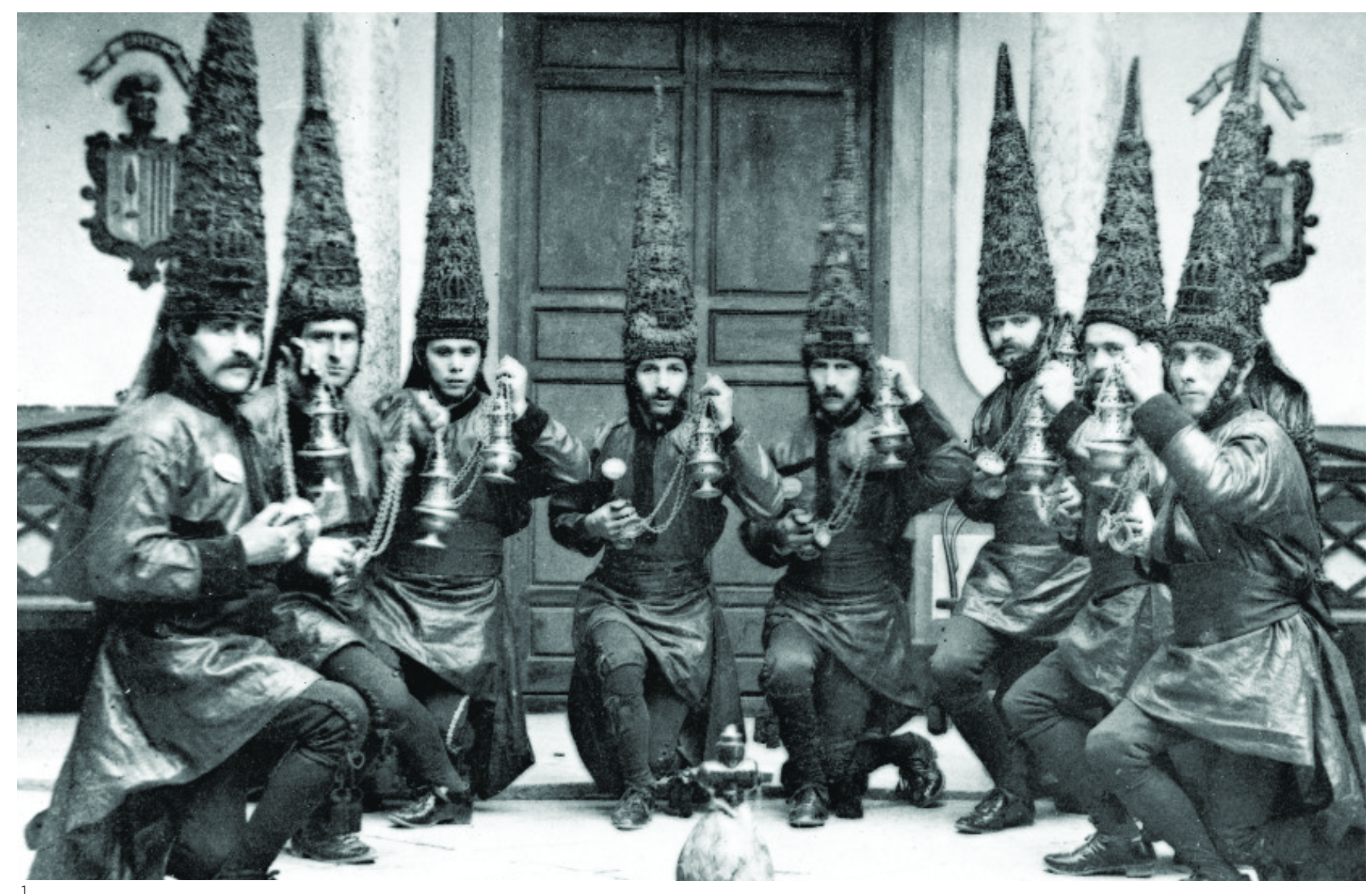

En cualquier caso, no debemos confundir los datos de participación con los de la efectividad del programa, que como sabemos, trabaja -y cada día más- con sectores de población especialmente complejos a la hora de su inserción laboral: etnias minoritarias y marginales, jóvenes instalados en el fracaso escolar (cuando no desescolarizados), y/o con especiales dificultades de integración social, y/o con problemas de estructuración familiar, etc. Con este capital humano, especialmente sensible, los datos aportados por el INEM entre 1989 y 2002 (estos últimos publicados en 2004), en cuanto a la evolución de la inserción laboral de los alumnos trabajadores, arroja las cifras que se recogen en la tabla 2.

Parece destacable la caída que significó el ejercicio 1992, con sus más de 14 puntos porcentuales de descenso de la inserción laboral (también fue un año recesivo en lo que se refiere a la evolución de la participación total de alumnos-trabajadores), lo mismo que el remonte sostenido experimentado desde 1997, que pone en evidencia un pobre balance de la evolución 1989/96 (-1,42\%), frente al balance (+22,91\%) que significó el periodo 1996/2002. La inserción laboral femenina, que inició su periplo por el programa con un índice 20,8 puntos inferior al masculino, en 2002 había reducido la diferencia hasta los 10,03 puntos.
Desde el punto de vista exclusivamente laboral, los indicadores de inserción parecen apuntar objetivamente al mayor éxito del programa durante el periodo en que los proyectos locales pasaron a diversificar el objeto de sus acciones, reduciendo la importancia relativa de los proyectos patrimoniales como elemento primordial y casi único de atención, para abarcar otra tipología de acciones no necesariamente vinculadas a la intervención sobre los bienes culturales.

Los datos que se refieren a la relación entre la inserción laboral y el tipo de formación recibida por el alumnado en el programa de ET-CO correspondiente al año 2002 (tabla 3) ponen de manifiesto que del conjunto de los jóvenes alumnos colocados $(76,61 \%$ de los participantes), el 39,10\% lo hizo en trabajos relacionados con las enseñanzas recibidas durante su periodo formativo en el programa; lo que quiere decir que un $70 \%$ del total de los alumnos participantes (incluidos los no colocados) no alcanzaron sus objetivos iniciales de formación-empleo, ya fuera porque no accedieron a un puesto de trabajo, ya porque el modo de empleo conseguido en nada tuviera relación con la instrucción recibida.

En cualquier caso, no menos relevante resultaría una tercera realidad asociada a este objetivo de creación de empleo; me refiero 


\section{Investigación}

Territorio, patrimonio y empleo: una visión local ante el estado de la cuestión global

\section{J . A. Sánchez Martínez}

a la emergencia de un nuevo yacimiento de trabajo, el que pudo explotar una joven generación de profesionales del patrimonio en sus diferentes facetas-, que ya fuera como docentes, como directivos, o como colaboradores de los programas de ET-CO, tuvieron la posibilidad de vislumbrar una nueva forma de aplicar su formación universitaria: la gestión de los recursos patrimoniales en el ámbito local al servicio del desarrollo, experimentando con el tiempo metodologías de puesta en valor pocas veces ensayadas dentro de las aulas de sus facultades de origen.

El año 1991 significó la puesta en marcha de la Iniciativa Comunitaria LEADER I, con el objetivo primordial de profundizar en nuevas y posibles vías de diversificación de la economía de las zonas rurales europeas. El lucimiento del programa en aquellas regiones que se aplicara -las que "a priori" contaban con las más fiables mimbres de éxito-, facilitó su continuidad durante el periodo 1994-1999 (LEADER II), en esta ocasión junto con el denominado Programa de Desarrollo y Diversificación de Zonas Rurales (PRODER), iniciativas ambas que finalmente vuelven a prorrogarse durante el periodo 20002006 bajo los enunciados respectivos de LEADER PLUS y PRODER de Andalucía.

\section{Tabla 1}

\begin{tabular}{llll} 
Año & $\begin{array}{l}\text { Total de } \\
\text { participantes }\end{array}$ & Hombres (\%) & Mujeres (\%) \\
1998 & 6.467 & 63,31 & 36,69 \\
1990 & 9.625 & 60,67 & 39,33 \\
1991 & 22.715 & 61,12 & 38,88 \\
1992 & 19.177 & 56,94 & 43,06 \\
1993 & 20.077 & 60,01 & 39,99 \\
1994 & 16.141 & 62,70 & 37,30 \\
1995 & 14.099 & 69,44 & 30,56 \\
1996 & 22.919 & 71,65 & 28,35 \\
1997 & 24.755 & 69,66 & 30,34 \\
1998 & 23.194 & 68,51 & 31,49 \\
1999 & 31.446 & 62,26 & 37,74 \\
2000 & 26.880 & 63,50 & 36,50 \\
2001 & 25.835 & 63,93 & 36,07 \\
\hline
\end{tabular}

Tabla 1. Datos de evolución de la participación en el Programa de Escuelas Taller y Casas de Oficios (INEM)

Tabla 2. Datos de evolución de los índices de inserción laboral del Programa de Escuelas Taller y Casas de Oficios (INEM)

Tabla 3. Datos de distribución porcentual de las colocaciones según la relación de la ocupación con la formación y experiencia recibidas en el Programa de Escuelas Taller y Casas de Oficios (INEM), 2002
En el medio-largo plazo que han significado los catorce/once años respectivos de aplicación de estos programas comunitarios, todos los indicadores objetivos y subjetivos parecer apuntar en la dirección de que, en la práctica, estamos ante las más exitosas experiencias de desarrollo territorial del continente en términos de eficiencia (costos/resultados), habiendo constituido un referente inmejorable sobre lo que significan algunas evidencias:

$>$ Estos programas han contribuido, como ningún otro, a difundir la percepción ciudadana de pertenencia a la Unión (territorio global) como algo tangible, como algo más allá de un mero concepto simbólico o histórico.

$>$ LEADER y PRODER están siendo gestionados, especialmente en su actual y tercera fase de implantación, por entidades sin ánimo de lucro conformadas al amparo del denominado tercer sector, organizadas con un criterio de paridad entre los agentes públicos y privados del territorio. Ambas iniciativas han favorecido con ello la creación de estructuras de gestión del desarrollo local "in situ", los denominados CEDER (antes conocidos como Grupos de Acción Local), integradores del conjunto de los intereses sociales y de las potencialidades de cada geografía, y que han sido los verdaderos dinamizadores y corres-

\section{Tabla 2}

\begin{tabular}{|llll|}
\hline Año & $\begin{array}{l}\text { Inserción } \\
\text { laboral (\%) }\end{array}$ & $\begin{array}{l}\text { Inserción } \\
\text { masculina (\%) }\end{array}$ & $\begin{array}{l}\text { Inserción } \\
\text { femenina (\%) }\end{array}$ \\
$\mathbf{1 9 9 8}$ & 60,26 & 66,34 & 45,54 \\
1990 & 61,96 & 68,34 & 49,97 \\
1991 & 55,61 & 65,47 & 37,44 \\
1992 & 41,50 & 53,47 & 28,56 \\
1993 & 42,15 & 52,17 & 29,95 \\
1994 & 50,10 & 60,41 & 35,39 \\
1995 & 56,88 & 66,33 & 39,47 \\
1996 & 58,84 & 65,85 & 44,18 \\
1997 & 66,73 & 73,89 & 51,28 \\
1998 & 69,73 & 75,95 & 57,56 \\
1999 & 69,38 & 78,63 & 56,43 \\
2000 & 76,96 & 83,04 & 66,50 \\
2001 & 77,19 & 82,49 & 67,90 \\
2002 & 81,75 & 67,16 & 77,19 \\
\hline
\end{tabular}

\begin{tabular}{|c|c|c|c|c|c|c|c|c|c|}
\hline \multirow[t]{2}{*}{ Relación ocupación/formación } & \multicolumn{3}{|c|}{ Escuelas Taller } & \multicolumn{3}{|c|}{ Casas de Oficios } & \multicolumn{3}{|c|}{ Total ET/CO } \\
\hline & H \% & M \% & TOTAL & H \% & $\mathbf{M} \%$ & TOTAL & $\mathrm{H} \%$ & M \% & TOTAL \\
\hline $\begin{array}{l}\text { Relacionada } \\
\text { No relacionada }\end{array}$ & $\begin{array}{l}49,60 \\
50,40\end{array}$ & $\begin{array}{l}16,39 \\
83,61\end{array}$ & $\begin{array}{l}40,01 \\
59,99\end{array}$ & $\begin{array}{l}42,18 \\
57,82\end{array}$ & $\begin{array}{l}22,10 \\
77,90\end{array}$ & $\begin{array}{l}33,62 \\
66,38\end{array}$ & $\begin{array}{l}48,72 \\
51,28\end{array}$ & $\begin{array}{l}17,51 \\
82,49\end{array}$ & $\begin{array}{l}39,10 \\
60,90\end{array}$ \\
\hline
\end{tabular}


2. El paisaje rural se manifiesta como un contenedor de activos patrimoniales con alta capacidad de seducción en medio del territorio. Paisaje del entorno de Medina Sidonia (Cádiz). Imagen: Juan Alonso Sánchez

ponsables de las propuestas de desarrollo puestas en práctica en cada lugar. LEADER y PRODER han puesto sobre la mesa la distinta capacidad de los territorios para autogestionar su propio devenir bajo criterios de sostenibilidad y participación.

$>$ Estas iniciativas han contribuido a estructurar no sólo instrumentos de participación social para el desarrollo, sino que en muchos casos, han despejado ambigüedades en el mapa comarcal de Andalucia, definiendo o corrigiendo "de facto" agrupaciones de municipios o diseños de comarcalización históricos dificilmente encajables con el presente y con el futuro desde una óptica económica.

$>$ Las marcas de programas europeos LEADER y PRODER han constituido una referencia de valorización de los recursos propios del territorio rural sin precedentes -creo no exagerar-, hasta el punto de haber descubierto para muchos habitantes del medio local el significado de términos como "endógeno" o "autóctono", y todo su derivado de sinónimos; también "patrimonio cultural" como un elemento más de la familia semántica.

Parece evidente, pues, que LEADER y PRODER han sido programas capaces de sustanciar una nueva dinámica de atención sobre el patrimonio cultural y natural de las regiones de Europa económicamente menos boyantes, tal es el caso de Andalucia: aportando conciencia e inversiones -en su conjunto mil millonarias- dedicadas a la rehabilitación de recursos patrimoniales; a la generación de productos y servicios asociados; generando renovadas ofertas y demandas sobre el territorio; impulsando dinámicas de consumo (gastronómico, artesanal, de alojamiento en inmuebles históricos o de arquitectura tradicional, de marcas específicas con denominación de origen, de servicios complementarios de ocio basados en la cultura y el medio ambiente...) en los que el protagonismo y la plusvalía no emigra; en definitiva, abriendo resquicios a otras posibilidades de empleo local.

Para los distintos grupos, hoy en día, el reto principal reside en la búsqueda de modelos y métodos que aproximen el concepto de excelencia a los ambientes locales en cada una de sus facetas cotidianas; también las relacionadas con la gestión de las políticas patrimoniales. La tendencia a desarrollar "cartas de calidad territorial" en cada uno de nuestros ámbitos posiblemente va a suponer, en el futuro inmediato, el ejercicio de reflexión y práctica gestora más fructífero de los últimos tiempos sobre el modo de encauzar la administración del desarrollo en los ámbitos rurales.

Entender y aplicar el concepto de calidad -de excelencia- no sólo a la producción o el diseño de bienes y servicios comerciales, sino también a los modos de gestión de los servicios públicos, a la calidad del empleo generado, e incluso al sistema de relaciones sociales y ciudadanas de un determinado micro-territorio, pone a los ambientes locales en el camino de imaginar un medio/largo plazo

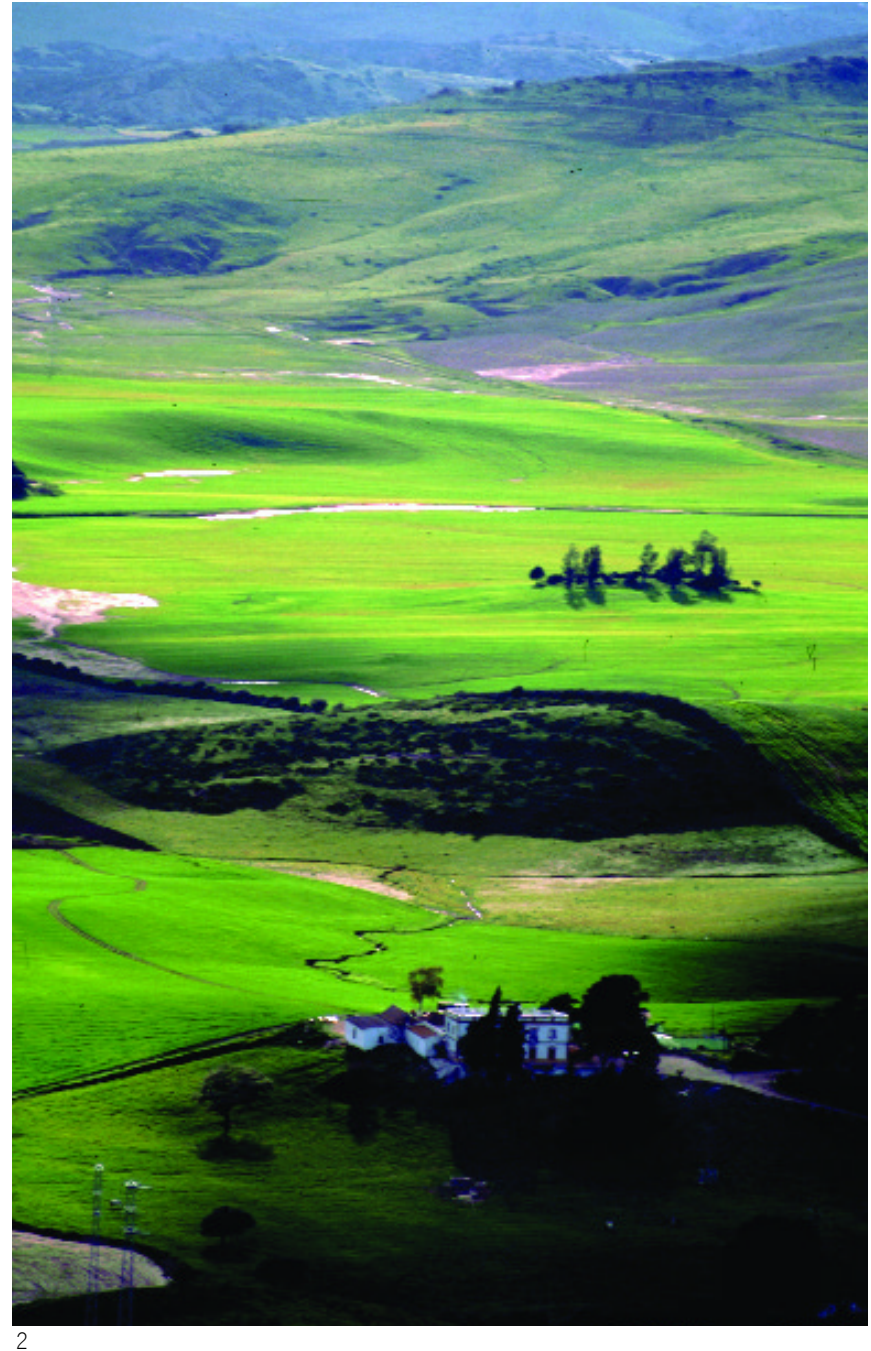

marcado por cotas de aptitud envidiables en materia de gestión cultural (museos, bibliotecas, espacios naturales y de interpretación, eventos efímeros...), que ya se apuntan, de hecho, en algunos ejemplos de municipios interiores de Andalucía.

En lo que respecta a la publicación de los balances de consolidación y generación de empleo que han significado -que están significando- estos dos programas en sus afecciones patrimoniales, cabe decir que nos enfrentamos a una imposibilidad todavía no resuelta, a pesar del empeño observatorio y documental de entidades de nuestro ámbito autonómico como la Asociación para el Desarrollo Rural de Andalucía (ARA).

Efectivamente, a la hora de alcanzar conclusiones, nos movemos en el vacio creado por la ausencia de cifras y balances de empleo publicadas "por medidas"; es decir, por temáticas o sectores de actividad específicos, si bien, cuantos participamos de un modo u otro de la gestión de estos programas sabemos de la elasticidad con la que están siendo catalogados los proyectos patrimoniales a la hora de su financiación, como propios de medidas del tipo "turismo rural" (LEADER I); "conservación y mejora del medio ambiente y del entorno", "turismo rural" (LEADER II); "valoración del patrimonio y del medio ambiente" (LEADER plus); "valorización del patrimonio rural", "renovación y desarrollo de pueblos", "fomento de las inversiones turísticas" (PRODER I); "protección y mejora del patrimonio y del medio ambiente" o "fomento, mejora y diversificación económica: sector agrario, artesanía y turismo rural" (PRODER Andalucia). 


\section{Investigación}

Territorio, patrimonio y empleo: una visión local ante el estado de la cuestión global

\section{J . A. Sánchez Martínez}

Los datos de empleo aportados por la tabla correspondiente (tabla 4) a los balances finales de los programas LEADER II y PRODER Andalucia (1994-1999) se refieren al conjunto de las medidas subvencionables, sin que por ello podamos inferir correlaciones fiables entre inversiones en materia de patrimonio y creación de empleo. El enigmático triángulo definido por los vértices "inversión-patrimonio rural-empleo" queda así tan sólo resuelto en dos de sus puntas (inversión-empleo), arrojando cifras más que alentadoras tanto en materia de puestos de trabajo de nueva creación, como de puestos consolidados mediante inversiones en mejora y modernización de empresas preexistentes.

Otra aproximación parcial al triángulo nos la aporta el trabajo de Pilar Tassara (2002), que disecciona provisionalmente la cuantía de las inversiones públicas que LEADER $\|$ ha realizado en Andalucía en materia de patrimonio y turismo rural (periodo 1994/99), agrupadas según diferentes tipologías (tabla 5). En este sentido, concluye el estudio por arrojar luz sobre otras dos de las esquinas de nuestro enigma (inversión-patrimonio rural), quedando sin reflejo el balance ocupacional, pendiente de futuras aportaciones estadisticas.

Constátese, en cualquier caso, que las mayores inversiones porcentuales se dirigen a los proyectos de naturaleza más "productiva" desde el punto de vista ocupacional, tales como los agrupados bajo los tipos "creación y mejora de equipamientos", "proyectos de puesta en valor" o "restauración y rehabilitación". Los grupos en los que tienen cabida iniciativas para creación de productos turísticos de naturaleza empresarial (hoteles, casas rurales, restaurantes, etc.) absorben el $63 \%$ de la ayuda procedente de fondos públicos, incluso aun cuando el porcentaje de subvención a este tipo de iniciativas no suele ir más allá del 30-35\% de la inversión total, corriendo el resto por cuenta del promotor.

En este sentido, e insistiendo en la circunvalación de datos a la que nos obliga la falta de estadísticas específicas, quizá debamos poner en cuarentena las cifras que nos aporta el INE en su encuesta de ocupación en alojamientos de turismo rural (ver tabla 6, correspondiente al último balance anual publicado, del año 2003). No parece muy probable -a la luz de la observación de campo- que una comunidad autónoma como la andaluza, avocada al cultivo del sector de los servicios, con una importancia relativa extraordinaria del subsector turístico (en torno al 20\% del PIB regional), y extendida sobre un $17,2 \%$ de la superficie del territorio español, no emplee más que al 6,3\% del total del personal ocupado en España -de forma remunerada o no remunerada- a la producción de bienes y servicios en establecimientos turísticos de alojamiento en el medio rural.

En relación a la cantidad/tipo de ocupación, cabe hacer una primera observación -válida tanto a nivel estatal como regional- sobre el porcentaje mayoritario de personas ocupadas sin retribución

\section{Tabla 4}

Total Andalucía (PRODER Y LEADER II)

№ de proyectos ejecutados

Coste total ejecutado

Ayuda pública total

206.442.212,78

Subvención comunitaria

$142.187 .851,01$

FEDER

$56.788 .269,15$

FSE

FEOGA-O

Administración nacional

Central

Autonómica

Local

Indicadores cuantitativos:

Empleos creados

Hombres

Mujeres

Total

Empleos consolidados

Empresas creadas

Empresas consolidadas

reconocida, hecho que no deja de ser elocuente en un doble sentido: por un lado, denota el predominio de un modelo de negocio de tipo familiar, en el que no siempre suele darse una equiparación justa entre la contribución a la actividad del conjunto de los miembros de la familia y su correspondiente recompensa económica; y por otro, la existencia de un alto porcentaje de personas ocupadas en la actividad sin el exigible reconocimiento laboral. De una y otra circunstancia se deduce un pobre nivel de rentabilidad económica en estos establecimientos, que requieren de la aportación de una fuerza de trabajo plural, para obtener un volumen de compensación económica y salarial bastante "singular".

Para ir concluyendo, más allá de la disparidad estadística que produce el carácter no reglado de la mayor parte de la oferta -diferencias incluso constatables en los datos aportados por los institutos estadisticos andaluz y estatal-, o de la falta de homogeneidad a la hora de abordar el sentido exacto del término "alojamientos de turismo rural", debemos reflexionar en voz alta sobre las posibilidades de generación de empleo que el medio/largo plazo puede 
Tabla 5. Fuente: TASSARA ANDRADE, Pilar. Programas de desarrollo rural y patrimonio: el impacto de los fondos europeos en Andalucía, en VI Jornadas Andaluzas de Difusión (2002)

Tabla 6. Tabla de elaboración propia. Fuente: encuesta de ocupación en alojamientos de turismo rural 2003 (INE). Se define al personal empleado como al conjunto de personas, remuneradas y no remuneradas, que contribuyen mediante la aportación de su trabajo, a la producción de bienes y servicios en el establecimiento, aunque trabajen fuera de los locales del mismo

\section{Tabla 5}

Inversión en turismo rural

13,9 millones euros

Tipología de proyectos

Investigación y documentación

Restauración y rehabilitación

Proyectos de puesta en valor

Proyectos de difusión

Creación y mejora de equipamientos
Inversión en patrimonio

8,6 millones euros
Inversión total

22.5 millones euros
(\%)

Catálogos, inventarios, informes, asistencias técnicas, estudios de viabilidad, planes estratégicos...

Restauración y rehabilitación de bienes culturales, especialmente inmuebles históricos.

Iluminación y señalización de monumentos, mejora de accesos, aparcamientos y del entorno, cubrición y $23 \%$ cerramiento de yacimientos...

Bienes editoriales (libros, folletos, guías...), festivales y eventos, jornadas y congresos, etc.

$10 \%$

Creación de instalaciones turísticas (restaurantes, casas y hoteles rurales...), museos, centros de $43 \%$ interpretación...

\section{Tabla 6}

Modalidades de ocupación

Personal empleado

Personal empleado no remunerado

Personal empleado remunerado fijo

Personal empleado remunerado eventual

Media mensual de personas ocupadas durante el año 2003 en alojamientos de turismo rural

Conjunto de España

11.196

$7.522(67,2 \%)$

$2.344(20,9 \%)$

$1.329(11,9 \%)$
Comunidad autónoma andaluza

710

$389(54,8 \%)$

$184(26,0 \%)$

$136(19,2 \%)$
Porcentaje andaluz sobre el conjunto del país

$6,3 \%$

$5,1 \%$

$7,8 \%$

$10,2 \%$ conferir a esta forma complementaria de renta familiar y de ocupación, tan necesitada de normalización, hecho al que también contribuyen los programas LEADER y PRODER, como incentivos económicos que son a la creación de empresas exclusivamente emergidas y sometidas a la norma.

¿Hasta qué punto podemos concluir en el reconocimiento de la oferta de patrimonio cultural como un elemento suficientemente motivador de la creación de empleo en el futuro del medio rural? Nuestro patrimonio, tan inserto en el resto de las realidades sociales y económicas del territorio, no arroja conteos de actividad laboral específicos que nos permitan su evaluación discriminada. A la luz de algunos otros indicadores circundantes de oferta y demanda de bienes y servicios relacionables, quizá podamos afinar el tino de nuestras conclusiones:

> Las encuestas de coyuntura turística de Andalucía relativas a las motivaciones del turista, realizadas sobre el año 2003, señalan que un $38,3 \%$ de los visitantes de nuestra comunidad autó- noma justificaron la causa de su viaje en atractivos compatibles con los valores patrimoniales del medio rural (fiestas populares, folklore, gastronomía, excursiones, calidad de vida, contacto con la naturaleza y visitas a monumentos). El dato no deja de resultar alentador si tenemos en cuenta que el destino turístico andaluz está fuertemente caracterizado por la oferta de aglomeración de sol y playa.

Es evidente que el producto cultural y patrimonial de la Andalucía rural interior puede y debe cultivar la estrategia de complementariedad turística, de producto "agregado", actuando como receptor reflejo de un veraneante costero (o de ciudad) que amplía progresivamente sus expectativas de ocio vacacional hacia el patrimonio interior (visitas a pueblos pintorescos, parques naturales, rutas culturales...) en busca de diversificación. Observando el fenómeno exclusivamente desde la óptica de la creación y consolidación de empleo -consideraciones conservacionistas aparte-, algunas de sus repercusiones directas e indirectas son perceptibles en distintas geografías rurales de la circunvalación litoral o urbana: en la recon- 


\section{Investigación}

Territorio, patrimonio y empleo: una visión local ante el estado de la cuestión global

\section{J . A. Sánchez Martínez}

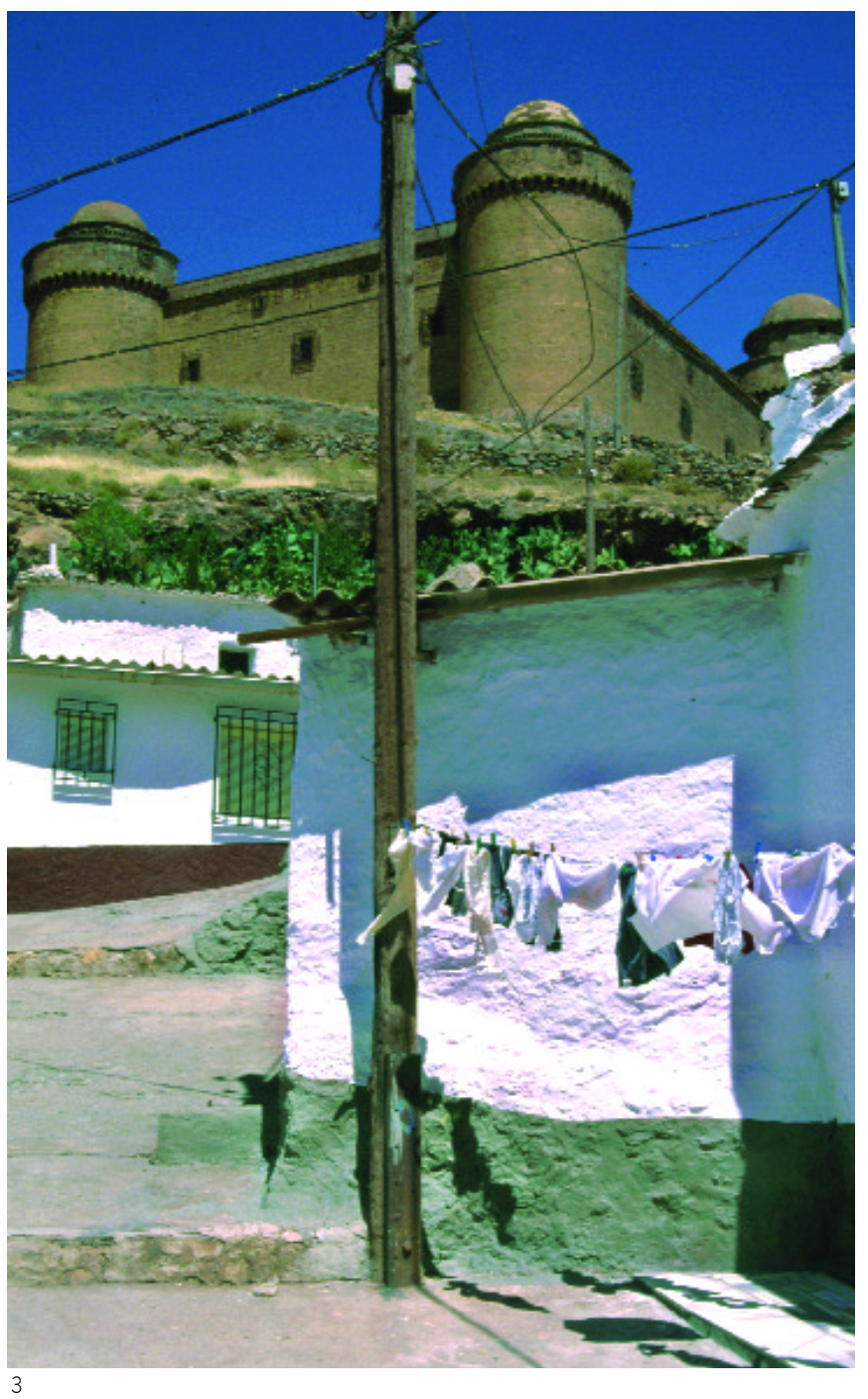

versión de buena parte de la mano de obra agraria desocupada hacia el sector hostelero y de la restauración; en la activación del sector constructivo, de tanta incidencia ocupacional en nuestra tierra; en la dinamización del pequeño comercio rural con forma de negocio familiar, etc.

Si esto es así, si cierto grado de "vinculación" respecto a los productos consolidados -costeros o urbanos- asegura logros económicos y ocupacionales a corto-medio plazo, no resulta menos cierto que la especificidad del producto, su potencial en Andalucía, y la tendencia sostenida al incremento de la demanda de turismo rural y patrimonial, obliga a profundizar en el diseño de estrategias de desarrollo turístico específicas y propias para este medio, tanto en materia de dotación de equipamientos de alojamiento y restauración (pautas de calidad y tradición), como de sistemas de distribución (nuevas aplicaciones tecnológicas), como de metodologías de interpretación terri- torial, como de capacitación profesional del sector, como de compatibilidad laboral para sus profesionales con los oficios tradicionales (mecanismos de pluriocupación normalizados)...

> Para el mismo año 2003, el Anuario Estadístico de Andalucía contabiliza una oferta total de 4.070 plazas de alojamiento rural repartidas en un conjunto de 579 establecimientos (3.282 y 379 respectivamente para el INE), lo que viene a aportar una media de 8,6 plazas por unidad de alojamiento. Considerando el modelo de microempresa que resulta, y un grado de ocupación para el mismo año del 20,59\% (fuente INE), no parece necesario invertir más líneas en valorar el nivel de rentabilidad económica del turismo rural en el sector del alojamiento, y su escasa repercusión en la generación de empleo directo.

La capacidad de generación/cualificación de empleo que conlleva el modelo de equipamiento conocido popularmente como "casa rural" es más que relativa; en parte, como ya hemos dicho, por su escasísima rentabilidad; en parte, en muchos casos, por la deficiente mentalidad empresarial de la propiedad; y en parte, por la espectacular bolsa de oferta no reglada, que da lugar a unas formas de ocupación ajenas a toda lógica normativa. En este sentido, el establecimiento del tipo "pequeño hotel rural con encanto" -con servicios de restaurante incluidos-, ofrece una serie de valores añadidos para la rentabilidad y el empleo de más altos vuelos: mayor exigencia de profesionalidad, mayor contratación reglada, más amplia oferta de servicios y productos complementarios (gastronomía, venta de productos artesanales, visitas guiadas...), valor fiscal de los ingresos como renta de naturaleza turística (no de arrendamiento inmobiliario), etc.

$>$ La evolución del número de visitantes a conjuntos monumentales y arqueológicos de Andalucía en el periodo 1991-2002 se ha incrementado en un 29,4\%, pasando de 319 a 452 visitantes por cada mil habitantes; esto es, una tendencia al alza del 2,6\% anual. Esa misma evolución, para el mismo periodo, respecto a las visitas a museos, arroja un porcentaje de incremento del 38,3\% (+3,5\% anual). Nuestro sector patrimonial no parece avanzar muy a la zaga del desarrollo turístico andaluz de los últimos años si tenemos en cuenta que, para el periodo 1994-2002, las cifras de viajeros registradas en nuestros establecimientos hoteleros pasaron de los 6,2 a los 11,4 millones de entradas (incremento del $45,1 \%)$, con un porcentaje de incremento del 5,6\% anual (Elaboración propia. Fuente: Indicadores Sociales de Andalucía. Hábitos Culturales. IEA).

Parece evidente que la demanda creciente del sector turístico puede estar repercutiendo -junto con otros factores- en el lento y sostenido crecimiento de usuarios de nuestros conjuntos monumentales, arqueológicos y museos. El interés por el consumo del producto patrimonial es progresivo, hecho que desarrolla expectativas de empleo en el sector, nuevos yacimientos de empleo cuali- 
3. La presentación del patrimonio como elemento de atractivo turístico debe ser interpretada. Dos arquitecturas, dos mundos... y toda una historia que trasladar al visitante. Castillo de la Calahorra (Granada). Imagen: Juan Alonso Sánchez 4. Curso de formación de guías turísticos del Poniente Granadino. Castillo de Moclín (Granada). Imagen: Juan Alonso Sánchez

ficado que orbitan en torno a la puesta en valor de los bienes culturales y de su conservación.

> Un total de 101 equipamientos museísticos de los 149 inscritos en el Directorio de Museos de Andalucia del Ministerio de Cultura están radicados fuera de las capitales de provincia (67,8\%). Si tenemos en cuenta que Andalucía suma un total de 762 municipios no capitalinos, obtenemos un resultado relativo de un museo por cada siete localidades, dato que no parece quedar muy lejos de lo razonable. Quizá la insistencia en este sentido deba apuntar en la dirección de incrementar la dotación de personal de estos equipamientos, ya que la práctica habitual de la visita suele poner en evidencia notables limitaciones de diseño, gestión y mantenimiento, derivadas de un insuficiente esfuerzo en el capitulo presupuestario dedicado a gastos de personal: déficit formativo, desprofesionalización, plantillas mínimas, duplicidad de funciones, etc. (Elaboración propia. Fuente: Ministerio de Cultura).

La creación de productos y servicios patrimoniales, tal es el caso de museos, centros de interpretación o visitantes, itinerarios culturales o servicios de guías, constituye un indicador más que fiable de la apuesta por el desarrollo local de un territorio, del tributo a la generación de empleo desde el ámbito de las políticas culturales, una de cuyas principales razones de ser radica en su contribución al desarrollo integral, social y económico del entorno geográfico.

> Según el Instituto Estadístico de Andalucía, el gasto público para la cultura previsto en los presupuestos autonómicos durante el periodo 1989-2003 ha pasado de significar un 2,3\% a un 0,9\% del gasto público total. Si tenemos en cuenta que la preferencia presupuestaria general de los poderes públicos suele ir dirigida hacia los sectores de actividad con mayor capacidad de generación de empleo, por deducción, parece consecuente advertir que la cultura -más allá de los planes directores y los documentos estratégicosno es observada como un sector de actividad significativo a la hora de animar el mundo laboral.

En este contexto adquiere cada vez mayor relevancia el papel de los nuevos colectivos profesionales de la cultura y el patrimonio, tal es el caso de la Asociación Española de Gestores del Patrimonio Cultural (AEGPC), de la Asociación de Gestores Culturales de Andalucía (GECA), o de las secciones de Arqueología e Historia del Arte que crecen y se organizan al calor de algunos colegios profesionales, que deben ser capaces de reivindicar el papel y la importancia social y económica del profesional del patrimonio cultural en el contexto laboral actual, tanto del que está dentro de la administración, como del que está fuera de ella.

No es menos cierto que el sector privado de la cultura comienza a dar signos de vida inteligente, y que pese a las muchas dificultades que conlleva la creación de empresas con cierto margen de

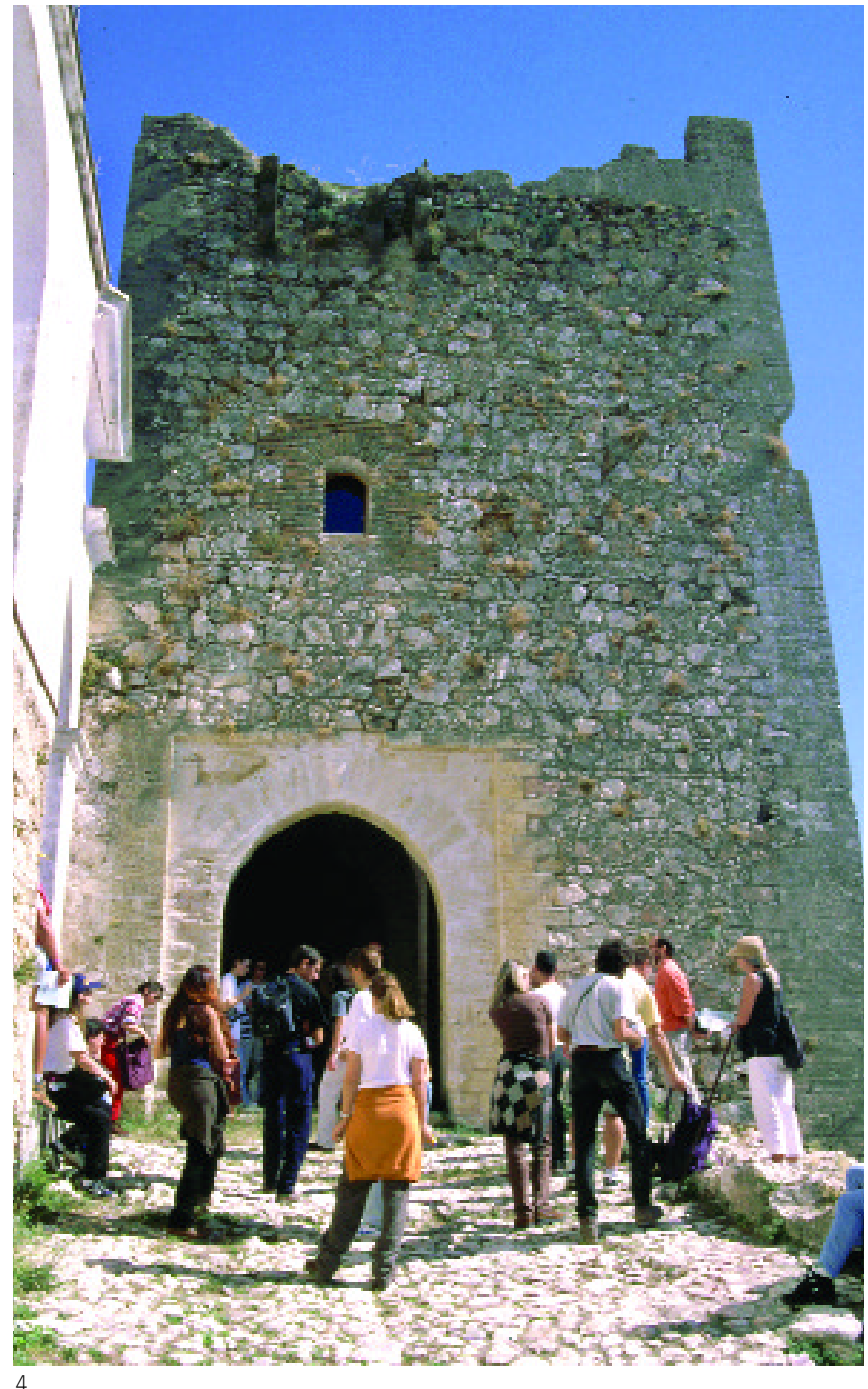

rentabilidad, cada día es mayor la nómina de profesionales, cooperativas y sociedades mercantiles de todo tipo que viven y sobreviven del manejo de los bienes culturales, cubriendo una demanda creciente de la sociedad contemporánea, que cada día se interrelaciona de mayor modo con su entorno patrimonial, y que requiere de servicios de asesoría técnica, de arqueología de gestión, de restauración, de planificación de productos territoriales, de diseño de proyectos museológicos, etc.

Atrás quedan las limitaciones impuestas al mercado laboral de los jóvenes profesionales del patrimonio por el monopolio de bastantes de nuestros departamentos universitarios, que con demasiada frecuencia extralimitaron sus funciones naturales -la docencia y la investigación-, para adentrarse intrusivamente en los terrenos propios del mercado profesional. Cabe reflexionar, siquiera de soslayo, sobre la licitud ética de este fenómeno, que ha atentado signi- 


\section{Investigación}

Territorio, patrimonio y empleo: una visión local ante el estado de la cuestión global

\section{J . A. Sánchez Martínez}

ficativamente contra las posibilidades de creación de empleo en el sector, y que paradójicamente, lo ha hecho valiéndose de una fuerza de trabajo mayoritariamente estudiantil -ávida de méritos-, profesionales potenciales, a la que al cabo de los años le competirá un espacio laboral al que tiene derecho.

Creo de justicia destacar en este mismo lugar la tenaz labor de instrucción y de información desarrollada en nuestra comunidad autónoma por el Instituto Andaluz del Patrimonio Histórico de la Consejería de Cultura, que anualmente pone en manos de los profesionales del patrimonio una oferta formativa y de renovación de conocimientos especializada, en la que subyace continuamente el valor del patrimonio cultural como elemento para la dinamización económica y del empleo.

$>$ El sector artesanal andaluz ofrece otro campo de ocupación importante relacionado con el patrimonio cultural, resultando significativo el nacimiento, en 1999, de la Federación de Artesanos de Andalucia (FADA), que hoy agrupa a un total de 294 talleres artesanos vinculados a 24 colectivos profesionales del sector en toda la comunidad autónoma, según informa su propia página web.

La demanda de valores de autenticidad vigente en las sociedades urbanas actuales hace del subsector artesanal del medio rural un terreno abonado para el crecimiento ocupacional, que abastece al visitante de productos ornamentales, alimenticios, de abrigo, y de toda indole, gravados con la plusvalia de "lo auténtico". Aquí volvemos a establecer paralelismos con el mundo del ecologismo, que ha sabido involucrar al sector productivo y comercial agroganadero en la generación de valores añadidos mediante la creación de un mercado (oferta/demanda) de "Io genuino". Cada día más, la producción alimentaria ecológica cotiza al alza, crece la nómina de marcas específicas con denominación de origen, o se amplía el número de organismos y consejos reguladores de calidad en el medio rural, todos ellos indicadores del potencial de productividad económica del distintivo "producto libre de adulteración".

El sector de actividad del patrimonio cultural, y por ende, el ámbito artesanal del medio rural, debe seguir el ejemplo -una vez másde las políticas trazadas en el marco del patrimonio natural, que se ha sabido involucrar con más solvencia y mayor eficacia en la dinámica social impuesta por el correr de los tiempos.

Concluyamos finalmente insistiendo en la percepción del patrimonio cultural como un recurso más al servicio del desarrollo individual y colectivo de las personas que habitan un territorio, de su calidad de vida, de su catálogo de valores, de su nivel de conocimiento y de sensibilidad, de su derecho al empleo, de su conciencia del paisanaje y de su sentido de pertenencia cultural a una circunstancia espacial y temporal determinada. Es necesario -lo dice la Agenda 21 de la Cultura- destacar la importancia de la cultura como factor de generación de riqueza y desarrollo económico (Art. 12) desde prácticas de buen gobierno, de respeto y de evaluación permanente de nuestras acciones, apoyadas en la multiplicidad de los agentes sociales con voluntad de transparencia informativa y participación ciudadana (Art. 5).

Los contextos locales se constituyen como agentes culturales de primer orden, y el concepto de ciudadanía, como principio social, ha dejado de ser patrimonio exclusivo de las urbes. El medio rural ensaya y practica estrategias especificas para la gestión y puesta en valor de sus recursos patrimoniales (Cuenca Minera de Riotinto, Almedinilla, Carmona, Loja, Serranía de Ronda...), y dentro de ellas, la generación de empleo no debe ocupar espacios baladies. Desde esta realidad se hace necesario el diseño de mecanismos de evaluación también propios y específicos, que permitan concluir en grados de eficacia económica y ocupacional.

Los distintos programas de intervención sobre el patrimonio cultural implantados en el ámbito local-rural deben reforzar sus aspectos de control de calidad, de sentido estratégico y de impacto sobre el entorno social, definiendo sus propios indicadores de evaluación en clave cuantificada y objetivamente mensurable. Debemos ser capaces de demostrar -con el menor margen de especulación posible y hasta más allá de lo que lo hacen los actores patrimoniales del contexto urbano, ya que el margen de confianza es menor-, las relaciones directas de causa-efecto que se contienen en el binomio "inversión en cultura-avance social y laboral".

Subsectores de actividad como el turismo rural, la producción y comercialización artesanal, la gestión de equipamientos, servicios y territorios culturales y naturales, la restauración de bienes patrimoniales... constituyen hoy en día un yacimiento de empleo que, si bien no vaya a representar un milagro económico y ocupacional en el conjunto del medio local, sí pueden significar un suma y sigue de clara incidencia en los procesos de desarrollo que ya estamos conociendo.

Debo insistir, para concluir en la redondez del texto, en la idea y en la forma literaria a la que ya recurriera en algún otro número de esta revista de referencia para el sector profesional del $\mathrm{PH}$. Lejos de panaceas redentoras, de causas únicas, los bienes culturales vienen a sumar un elemento más a las dinámicas de cambio y de mejora social en el medio rural; son una nueva contribución de la actualidad -pero sólo una más- al agregado de factores que deben posibilitar una forma de vida y de ocupación libremente elegida por el habitante del medio rural. Sigamos indagando en el avance social según la máxima utópica, mosquetera y sostenible de Alejandro Dumas: todos para uno, y uno para todos. 